\title{
Gegen die moderne Welt: Die geheime Geistesgeschichte des 20. Jahrhunderts
}

\author{
Mark Sedgwick \\ Berlin 2019: Matthes \& Seitz, 549 S.
}

\section{Mario Wintersteiger}

FB Politikwissenschaft und Soziologie, Universität Salzburg

E-Mail: mario.wintersteiger@sbg.ac.at

Mit Gegen die moderne Welt liegt nun das Standardwerk zur Geschichte des Traditionalismus in deutscher Übersetzung vor. Wer sich vom Untertitel („geheime Geistesgeschichte") nicht irreführen lässt, wird bemerken, dass es sich hier nicht um eine Sammlung von Verschwörungstheorien, sondern um einen gut recherchierten Beitrag zur religiösen und politischen Ideengeschichte handelt.

Wichtig ist hervorzuheben, dass dabei nicht von „Traditionalismus“ im landläufigen Sinn die Rede ist, sondern von jenem „in einem spezifischeren Sinn“ (43), wie er sich in der Philosophie von René Guénon ausgeprägt hat. Das Profil dieser Denkschule sei hier kurz umrissen: Laut Mark Sedgwick entsteht der Traditionalismus durch die Kombination von drei Elementen: (i.) dem „Perennialismus“, einer Position, für die alle traditionellen Religionen unterschiedliche Formen derselben einen Ur-Tradition sind; (ii.) der Bewertung der Moderne als „Inversion“, das heißt als Prozess des Niedergangs, (iii.) der „Initiation“, dem Versuch, den befürchteten „Untergang des Westens" dadurch abzuwenden, indem man die im Westen verloren gegangene Überlieferung im Osten wieder aufspürt und so dem Westen erneut eine darin geschulte Elite verfügbar macht (vgl. 46-50).

Obwohl Guénon pessimistisch war, was die Erfolgsaussichten anging und er davor warnte, verfrüht politisch aktiv zu werden (vgl. 50 f.), konnte er nicht verhindern, dass es zur Herausbildung eines "politischen Traditionalismus" (I3) kam, wie er etwa von Julius Evola vertreten wurde. Dieser hatte, wie Sedgwick berichtet, mehrere Anläufe unternommen, den Faschismus zu infiltrieren, um dessen Ideologie durch traditionalistische Grundsätze zu ersetzen, was ihm jedoch nicht gelang (vgl. I49-I66); das Scheitern seines Planes hatte aber zur Folge, dass er seither - trotz der ideologischen Unterschiede - mit dem Stigma des „Faschisten“ belegt ist (vgl. 154 f.; 164 f.). All das hatte auch Auswirkungen auf seine Rezeptionsgeschichte (vgl. dazu 263-274). Doch macht Sedgwicks Analyse klar, dass es zu einfach wäre, den Traditionalismus auf seine politischen Irrwege zu reduzieren. Ihn undifferenziert zu betrachten, verbietet sich schon auf Grund seiner Vielfältigkeit, von der das Buch Zeugnis ablegt.

Gegen die moderne Welt versteht sich nicht als umfassende Einführung in die "philosophia perennis" (46) - man erfährt überraschend wenig über deren Details. Sedgwick gibt eine Einführung in ihre Grundzüge (vgl. z. B. 44-54), soweit diese für das Verständnis notwendig sind; ansonsten verweist er Interessierte auf die Primärquellen (vgl. 429). Das Hauptaugenmerk seines Buches liegt auf der Entstehung und Ausbreitung des Traditionalismus im 20. Jahrhundert, seinen politischen Verwicklungen sowie der nach 1968 enorm angewachsenen Vielfalt seiner Formen. Spuren und Spielarten der "philosophia perennis“ findet Sedgwick nicht nur bei „rechten Anarchisten“ (vgl. 266-27I) und in der russischen Geopolitik (vgl. bes. $334 \mathrm{ff}$.), sondern auch bei unorthodoxen Feministinnen (vgl. 315-319) und in der "grünen Bewegung" (vgl. $308 \mathrm{ff}$.).

Sedgwicks Werk ist eine faszinierende Lektüre. Die für wohl viele ungewöhnliche Thematik, die Übertreibung im Untertitel, der forschungsbiographische Prolog (vgl. I7-39), der im Stil einer "Detektivgeschichte“ (Schutzumschlag) erzählt wird, und Sedgwicks Neigung, seine Darstellung mit unterhaltsamen, mitunter bizarren Details aufzulockern, mag manchen skeptisch 
stimmen. Doch lässt ein Blick auf den üppigen Anmerkungs- und Quellenapparat keinen Zweifel daran zu, dass seine Einsichten fundiert sind.

Da das Buch kein genuin politikwissenschaftliches ist, seien hier ein paar Bemerkungen zur Frage hinzugefügt, welchen Wert es für unsere Disziplin haben könnte: Auf der Hand liegen dürfte der Nutzen der Hintergründe zum politischen Traditionalismus und seiner Geopolitik. Daneben erinnert uns Sedgwick aber auch daran, dass es neben der "strengen“ Variante des Traditionalismus auch noch eine "gemäßigte“ bzw. „sanfte“ Auslegung gibt, die um akademische Seriosität bemüht ist (vgl. I69 f.) und auf eine säkulare „philosophia perennis" hinausläuft (vgl. 17I). Da sich die Auseinandersetzung mit Letzterer in den Religionswissenschaften, aber auch in der Soziologie als einflussreich erwiesen hat (vgl. dazu 275-282), könnte es sich lohnen, ihre Bedeutung für eine vergleichende „Religionspolitologie“ (Bärsch 2005) auszuloten.

Die deutsche Ausgabe unterscheidet sich von der englischsprachigen (Sedgwick 2009) in erster Linie dadurch, dass die Darstellung des russischen Traditionalismus angewachsen ist. Inhaltlich deckt das Buch die Ereignisse bis $2006 \mathrm{ab}$, womit freilich ein Zeitraum von mittlerweile fast eineinhalb Jahrzehnten im Dunklen bleibt. Dass "die Zeit für eine Neuauflage" (Io) kommen wird, wie Sedgwick ahnt (vgl. ebd.), scheint somit gewiss; die Entwicklungen der jüngeren Zeit haben dazu geführt, dass gerade der politische Traditionalismus wieder mehr Aufmerksamkeit erfährt. Zum „prominentesten Traditionalisten" (345) dieser Art dürfte mittlerweile auch jemand anderer als der von Sedgwick angeführte Alexander Dugin (vgl. ebd.) avanciert sein, nämlich Steve Bannon. ${ }^{\mathrm{I}}$

\section{Literatur}

Bärsch, Claus-E. (2005), Zweck und Inhalte der Religionspolitologie, in: Bärsch, Claus-E./Peter Berghoff/Reinhard Sonnenschmidt (Hrsg.), „Wer Religion verkennt, erkennt Politik nicht": Perspektiven der Religionspolitologie, Würzburg: Königshausen \& Neumann, IO-50.

Koffler, Keith (2017), Bannon: Always the Rebel, Washington: Regnery Publishing.

Sedgwick, Mark (2009), Against the Modern World: Traditionalism and the Secret Intellectual History of the Twentieth Century, New York: Oxford University Press.

I Der Einfluss von Guénon und Evola auf Bannon ist gut dokumentiert (vgl. dazu Koffler 2017, II2-I15). 